\title{
Editorial
}

\section{Children in public health nutrition}

We are pleased to have a diversity of international articles on children in this issue of Public Health Nutrition. These articles range from the health status of infants born to HIV-infected women in Tanzania to the iodine status of schoolchildren in the Principality of Liechtenstein.

In a study among children born to HIV-infected women in Tanzania, Mwiru et $a l^{(1)}$ use a prospective study design to demonstrate the health benefits of exclusive breast-feeding through the first 6 months of life. These benefits come in the form of significantly reduced respiratory and diarrheal morbidity. Their findings are, to put it colloquially, a 'kick in the pants' for programmes to more actively encourage exclusive as opposed to partial breast-feeding, even among women infected with HIV.

At the other end of the socio-economic spectrum is the principality-wide screening study of iodine deficiency among children in Liechtenstein. Hilty and Zimmerman ${ }^{(2)}$ find levels of mild iodine deficiency in their representative sample of schoolchildren. Their results are another kick in the pants. Socio-economic advantage - Liechtenstein enjoys the distinction of having the second highest per capita Gross Domestic Product in the world - does not automatically protect against nutritional deficiency. As the consequences of iodine deficiency, even at mild levels, are potentially serious, awareness and screening campaigns are certainly warranted.

Among other articles addressing the nutritional health of children in this issue are studies seeking new dietary measurement tools that can be used with children. Rankin et $a l^{(3)}$ present their evaluation of the relative validity of an FFQ for assessing dietary fluoride intake in children in a Midwestern state of the USA. Further, recognizing the dearth of instruments assessing healthy food knowledge among children, Zarnowiecki et al. ${ }^{(4)}$ developed a Healthy Food Knowledge Activity, in which 5-6-year-old children in Adelaide, Australia, were asked to classify a list of foods and drinks as either 'healthy' or 'unhealthy'. Their assessment of the activity/tool, also presented in this issue, indicates that even young children are able to distinguish healthy from unhealthy foods; it also calls attention to foods that children might incorrectly perceive as being 'healthy' or 'unhealthy'. Dietary assessment in adolescents is addressed in a study by Schap et $a l^{(5)}$. As part of their development of a mobile telephone food record - a novel dietary assessment tool using mobile phones with built-in cameras to help quantify food intake - they report on an evaluation of adolescents' abilities to identify foods and to estimate portion sizes. Their results suggest that digital images of meals may be useful in helping adolescents recall previous meals, although portion size estimation remains a challenge.

Other articles in this issue involve epidemiological associations with anthropometric measures: novel measures of meal patterns - an understudied dietary variable - in relation to BMI index among children in Finland ${ }^{(6)}$; overweight in relation to asthma and atopy among children in Brazil ${ }^{(7)}$; and in Spain, childhood underweight and weight gain during childhood to adolescence in relation to the metabolic syndrome in adulthood $^{(8)}$.

Finally, Maes et $a l^{(9)}$ present results of a pilot evaluation of a computer-based, tailored, nutrition intervention among adolescents attending schools in Vienna, Austria, Ghent, Belgium, Heraklion and Athens, Greece, Dortmund, Germany, and Stockholm, Sweden. Such intervention studies are of course important if we mean to bring nutrition and health knowledge to the people it is meant to benefit. Their findings provide a good base for future work to seek acceptable and effective ways to communicate this knowledge to children and adolescents.

Infectious disease and malnutrition continue to be significant sources of morbidity and mortality in low-income countries. At the same time, non-communicable diseases such as heart disease and cancer are the leading causes of death globally. In 2008, $80 \%$ of those deaths occurred in low- to middle-income countries ${ }^{(10)}$. For all of these problems - the persisting problems of infection and malnutrition and the rising problem of non-communicable diseases - preventive strategies need to occur early in life. Studies on children are important because they are the most vulnerable, and subject to the conditions of their environments. They are also a target for empowerment and intervention, and the more we can learn about how to do so, the better off we will all be.

Agneta Yngve Editor-in-Chief

Irja Haapala Allison Hodge Geraldine McNeill Marilyn Tseng Deputy Editors

\section{References}

1. Mwiru RS, Spiegelman D, Duggan C et al. (2011) Relationship of exclusive breast-feeding to infections and growth of Tanzanian children born to HIV-infected women. Public Health Nutr 14, 1251-1258. 
2. Hilty FM \& Zimmermann MB (2011) Schoolchildren in the Principality of Liechtenstein are mildly iodine deficient. Public Health Nutr 14, 1312-1314.

3. Rankin SJ, Levy SM, Warren JJ et al. (2011) Relative validity of an FFQ for assessing dietary fluoride intakes of infants and young children living in Iowa. Public Health Nutr 14, 1229-1236.

4. Zarnowiecki D, Dollman J \& Sinn N (2011) A tool for assessing healthy food knowledge in 5-6-year-old Australian children. Public Health Nutr 14, 1177-1183.

5. Schap TE, Six BL, Delp EJ et al. (2011) Adolescents in the United States can identify familiar foods at the time of consumption and when prompted with an image $14 \mathrm{~h}$ postprandial, but poorly estimate portions. Public Health Nutr 14, 1184-1191.

6. Lehto R, Ray C, Lahti-Koski M et al. (2011) Meal pattern and body mass index in 9-11-year-old children in Finland. Public Health Nutr 14, 1245-1250.

7. Matos SMA, Jesus SR, Saldiva SRDM et al.; SCAALA (Social Change, Asthma and Allergy in LatinAmerica) Study Group (2011) Overweight, asthma symptoms, atopy and pulmonary function in children of 4-12 years of age: findings from the SCAALA cohort in Salvador, Bahia, Brazil. Public Health Nutr 14, 1270-1278.

8. Pimenta AM, Beunza JJ, Sanchez-Villegas A et al. (2011) Childhood underweight, weight gain during childhood to adolescence/young adulthood and incidence of adult metabolic syndrome in the SUN (Seguimiento Universidad de Navarra) Project. Public Health Nutr 14, 1237-1244.

9. Maes L, Cook TL, Ottovaere C et al:; on behalf of the HELENA Study Group (2011) Pilot evaluation of the HELENA (Healthy Lifestyle in Europe by Nutrition in Adolescence) Food-O-Meter, a computer-tailored nutrition advice for adolescents: a study in six European cities. Public Health Nutr 14, 1292-1302.

10. World Health Organization (2011) New WHO report: deaths from noncommunicable diseases on the rise, with developing world hit hardest. Noncommunicable diseases a two-punch blow to development. News release, 27 April. http://www.who.int/mediacentre/news/releases/2011/ncds_ 20110427/en/index.html (accessed May 2011). 